\title{
A Contrastive Study of Chinese Learners'Acquisition of English Non-alternating and Alternating Unaccusative Verbs
}

\author{
Junhua Mo \\ School of Foreign Languages, Soochow University, China
}

\begin{abstract}
English unaccusative verbs pose great difficulties to second language learners. The distinction between non-alternating and alternating unaccusative verbs makes the learning task even more difficult. This study conducts a contrastive study of how Chinese learners acquire these two types of verbs in terms of acquisition sequence, acquisition problem and developmental patterns. It finds that non-alternating and alternating unaccusative verbs are completely different from each other in acquisition sequence and acquisition problem, but are partly different in developmental patterns.
\end{abstract}

Index Terms-Second language acquisition, non-alternating unaccusative verbs, alternating unaccusative verbs, acquisition sequence, acquisition problem, developmental patterns

\section{INTRODUCTION}

The Unaccusative Hypothesis (Burzio, 1986; Perlmutter, 1978) postulates that intransitive verbs are not homogeneous, but consist of two sub-classes, namely unaccusative verbs (e.g. arrive, sink) and unergative verbs (e.g. laugh, walk). The surface subject of unaccusative verbs is the underlying object, while that of unergative verbs is the underlying subject. As far as English is concerned, the distinction between unaccusative verbs and unergative verbs is morphologically unmarked, because both types of verbs are canonically used in the active voice. Moreover, English unaccusative verbs can be further divided into non-alternating and alternating unaccusative verbs, depending on their ability to participate in transitivity alternation. The former can only be used as intransitive verbs (e.g. appear, exist) while the latter can also be used as transitive verbs without undergoing morphological changes (e.g. break, melt).

\section{LITERATURE REVIEW}

Zobl (1989) finds that English unaccusative verbs pose great difficulties to English as a second language (hence L2) learners. Three types of errors are reported. First is avoidance, which refers to L2 learners' reluctance to accept the intransitive use of non-alternating and alternating unaccusative verbs in the NP-V structure (e.g. A leaf fell or The fish burned in the oven). Second is passivization, which refers to L2 learners' production and acceptance of the passive use of non-alternating and alternating unaccusative verbs in the NP-Be-Ven structure (e.g. An accident was happened or The ice was melted). The third type is transitivization, which refers to L2 learners' production and acceptance of the transitive use of non-alternating verbs in the NP1-V-NP2 structure (e.g. The magician disappeared the dove).

Deguchi and Oshita (2004) note that the acquisition of unaccusative verbs is one of the most extensively studied L2 lexical issues. However, most of the previous studies focus on the distinction between unaccusative and unergative verbs. In contrast, studies that are devoted to the distinction between non-alternating and alternating unaccusative verbs are much smaller in number.

Sorace (1995) proposes the Unaccusative Hierarchy Hypothesis, which suggests that unaccusative verbs form a hierarchy ranging from core unaccusative verbs to peripheral ones. Moreover, core unaccusative verbs are acquired earlier than peripheral ones. According to this hypothesis, non-alternating unaccusative verbs are placed at the core of the hierarchy and are predicted to be acquired before alternating unaccusative verbs, which are peripheral. However, Ju (2000) finds that there is no difference between these two types of unaccusative verbs, because they are equally passivized by EFL learners.

Yip (1995) claims that non-alternating and alternating unaccusative verbs pose different acquisition problems. To acquire non-alternating unaccusative verbs, L2 learners need to expunge the ungrammatical passive use of these verbs from their interlanguage grammar. To acquire alternating unaccusative verbs, they need to functionally distinguish the intransitive use of these verbs from their passive use. Cai (2000) suggests that the acquisition of alternating unaccusative verbs is for L2 learners to acquire their intransitive use on the basis of their transitive use.

Oshita (2001) postulates the Unaccusative Trap Hypothesis, which states that L2 learners do not distinguish unaccusative verbs from unergative verbs when their proficiency is low. And they undergo a U-shaped developmental process in their acquisition of English unaccusative verbs. However, Hwang (19999) finds that L2 learners display a 
rising pattern in their rejection of the ungrammatical passive use of non-alternating unaccusative verbs, but a falling pattern in their acceptance of the grammatical intransitive use of alternating unaccusative verbs

Two points can be made about the previous studies. First, previous studies usually explored the acquisition sequence, acquisition problem and developmental patterns of non-alternating and alternating unaccusative verbs in a separate way. Second, no consensus has been reached over these three issues. It is therefore necessary to undertake a study that will include all these three issues so as to delineate a complete picture of L2 acquisition of non-alternating and alternating unaccusative verbs.

\section{Methodology}

\section{A. Research Questions}

This study had three research questions to answer. (1) Which type of unaccusative verbs do Chinese learners of different proficiency levels acquire first, non-alternating or alternating ones? (2) What kind of acquisition problems do non-alternating and alternating unaccusative verbs pose to Chinese learners of different proficiency levels? (3) What kind of developmental patterns do non-alternating and alternating unaccusative verbs follow?

\section{B. Subjects}

Four levels of Chinese English learners participated in this study. The low-level learners were $2^{\text {nd }}$-year students from Hua Luogeng High School in Jintan, Jiangsu Province, while the lower-intermediate learners were $3^{\text {rd }}$-year students from the same school. The intermediate learners were $2^{\text {nd }}$-year English majors from Suzhou University, Jiangsu Province, while the advanced learners were $1^{\text {st }}$-year graduate students of English from Nanjing University in the same province.

\section{Target Words}

This study chose six non-alternating unaccusative verbs (appear, arrive, exist, fall, happen, remain) and six alternating verbs (break, change, improve, increase, melt, sink) as its target words.

\section{Instruments}

Following Hwang (1999), this task adopted an acceptability judgment task and presented each target word in the NP-V, NP-Be-Ven and NP1-V-NP2 structures. For non-alternating unaccusative verbs, the intransitive use is grammatical, while the passive and transitive uses are both ungrammatical. For alternating unaccusative verbs, not only the intransitive use, but also the passive and transitive uses are grammatical.

Since this study was concerned with L2 acquisition of English unaccusative verbs, qualified subjects should, as suggested by Ju (2000), have acquired the rule of English passive voice. Therefore, twelve pseudo passive sentences (e.g. My bike stole yesterday) were included as distracters. All the test sentences and distracters were mixed and randomized. But sentences with the same target word were so ordered that they did not appear in adjacency. The subjects were asked to rate the acceptability of each sentence on a 5-point scale ranging from -2 to +2 .

\section{E. Data Processing}

The subjects were asked to provide the correct alternative when assigning a negative score. If their correction touched upon the real concern of the test sentence, their negative score would be retained. If their correction was irrelevant or unnecessary, their negative score would be changed into the corresponding positive score. In a word, the corrections the subjects made outweighed the scores they gave. Since the distracters were grammatical errors, they should be scored negatively. If a subject made three or more wrong judgements on the twelve distracters, he or she would be disqualified, resulting in the deletion of their data from the data pool. Finally, the low-level group had 33 qualified subjects, the lower-intermediate group 49, the intermediate group 43, the advanced group 29.

\section{RESULTS AND DiSCUSSION}

\section{A. Acquisition Sequence}

\section{Avoidance}

Table 1 shows that four levels of Chinese learners all accepted non-alternating unaccusative verbs in the NP-V structure significantly more often than they did with alternating ones. In other words, they overcame the problem of avoidance of non-alternating unaccusative verbs earlier than that of alternating ones.

TABLE 1:

PAIRED SAMPLES T-TESTS ON THE NP-V STRUCTURE

\begin{tabular}{lllllll}
\hline \multirow{2}{*}{ NP-V } & \multicolumn{2}{l}{ Non-alternating unaccusatives } & \multicolumn{2}{l}{ Alternating unaccusatives } & \multirow{2}{*}{$\mathrm{t}$} & \\
\cline { 2 - 5 } & $\mathrm{M}$ & $\mathrm{SD}$ & $\mathrm{M}$ & $\mathrm{SD}$ & 5.286 & .000 \\
\hline Low & 1.10 & 0.68 & 0.35 & 0.90 & 0.344 & .000 \\
\hline Lower-intermediate & 1.34 & 0.41 & 0.77 & 0.57 & .000 \\
\hline Intermediate & 1.61 & 0.61 & 0.89 & 0.61 & 5.620 & .000 \\
\hline Advanced & 1.83 & 0.19 & 1.45 & 0.51 & 3.668 & .001 \\
\hline
\end{tabular}




\section{Passivization}

Table 2 shows that four levels of Chinese learners all accepted non-alternating unaccusative verbs in the NP-Be-Ven structure significantly less often than they did with alternating ones. That is to say, they recovered from the error of passivization of non-alternating unaccusative verbs earlier than that of alternating ones.

TABLE 2:

PAIRED SAMPLES T-TESTS ON THE NP-BE-VEN STRUCTURE

\begin{tabular}{lllllll}
\hline \multirow{2}{*}{ NP-Be-Ven } & \multicolumn{2}{l}{$\begin{array}{l}\text { Non-alternating } \\
\text { unaccusatives }\end{array}$} & \multicolumn{2}{l}{ Alternating unaccusatives } & \multirow{2}{*}{$\mathrm{p}$} \\
\cline { 2 - 6 } & $\mathrm{M}$ & $\mathrm{SD}$ & $\mathrm{M}$ & $\mathrm{SD}$ & & \\
\hline Low & -0.30 & 0.82 & 0.62 & 0.90 & -6.823 & .000 \\
\hline Lower-intermediate & -0.42 & 0.96 & 0.35 & 0.76 & -6.963 & .000 \\
\hline Intermediate & -1.18 & 0.78 & 0.25 & 0.78 & -11.295 & .000 \\
\hline Advanced & -1.67 & 0.43 & 0.21 & 0.86 & -11.660 & .000 \\
\hline
\end{tabular}

\section{Summary of Avoidance and Passivization}

Summarizing the comparison between non-alternating and alternating unaccusative verbs with respect to avoidance and passivization, one can see that all levels of Chinese learners performed better on non-alternating unaccusative verbs than alternating ones. This suggests that they acquired non-alternating unaccusative verbs earlier than alternating ones.

\section{B. Acquisition Problem}

\section{Non-alternating Unaccusative Verbs}

For non-alternating unaccusative verbs, the NP-V structure is the only grammatical syntactic option, while the NP-Be-Ven and NP1-V-NP2 structures are both ungrammatical. To become target-like, Chinese learners should accept the NP-V structure, but reject the NP-Be-Ven and NP1-V-NP2 structures. Given the fact that Chinese learners were asked to score these structures on a 5-point scale ranging from -2 to +2 , the maximum correct score for non-alternating unaccusative verbs in the NP-V structure was +2 , while those for the NP-Be-Ven and NP1-V-NP2 structures were both -2 .

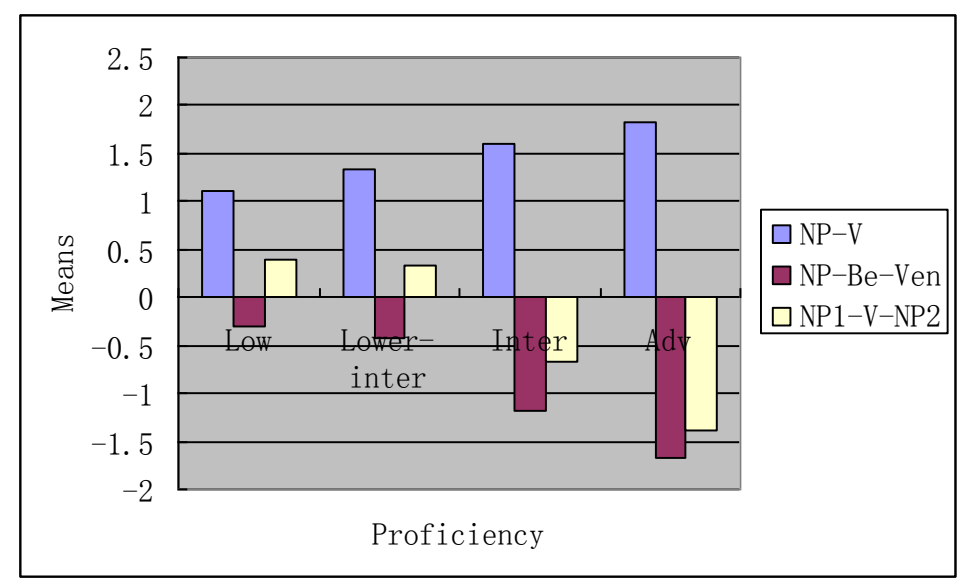

Figure 1: Means of Non-alternating Unaccusative verbs in Three Structures

Figure 1 shows that low-level Chinese learners' means of the grammatical NP-V structure was slightly above 1.0, which kept a relatively large distance from the maximum correct score of 2.0. Their means of the ungrammatical NP-Be-Ven structure was negative but was above -0.5 , which kept a very large distance from the maximum correct score of -2.0. Their means for the ungrammatical NP1-V-NP2 structure was positive, which was seriously deviant from the maximum correct score of -2.0. The low-level Chinese learners' pattern was roughly replicated by the lower-intermediate learners. In contrast, the intermediate and advanced learners' patterns were different. For one thing, their means of the grammatical NP-V structure became more and more positive. For another thing, their means of the ungrammatical NP-Be-Ven and NP1-V-NP2 structures became more and more negative. This suggests that Chinese learners at upper levels became more and more target-like in their judgments of non-alternating unaccusative verbs presented in different structures, grammatical and ungrammatical alike. That is to say, Chinese learners at upper levels could establish the correct argument and syntactic structure representations of non-alternating unaccusative verbs.

The differences between Chinese learners at lower levels and those at upper levels suggest that the acquisition of non-alternating unaccusative verbs was to reinforce the grammatical intransitive use of these verbs on the one hand and to expunge their ungrammatical passive and transitive uses on the other hand. This finding is more complicated than what Yip (1995) suggests in that she only touches upon the ungrammatical passive use, but makes no mention of the grammatical intransitive use and the ungrammatical transitive use. Therefore, the acquisition problem of non-alternating unaccusative verbs is more complex and more difficult than what Yip (1995) claims.

\section{Alternating Unaccusative Verbs}


For alternating unaccusative verbs, the NP-V, NP-Be-Ven and NP1-V-NP2 structures are all grammatically correct. However, the NP-Be-Ven structure was designed to be an inappropriate syntactic choice in the acceptability judgment task of this study. Since the contexts provided for alternating unaccusative verbs did not suggest an agent, it was infelicitous to use them in the NP-Be-Ven structure. To become target-like, Chinese learners should accept the NP-V and NP1-V-NP2 structures, but not to accept the NP-Be-Ven structure. Given the fact that Chinese learners were asked to rate these structures on a 5-point scale ranging from -2 to +2 , the maximum correct scores for alternating unaccusative verbs in the NP-V and NP1-V-NP2 structures were both +2 , while that for the NP-Be-Ven structure was -2 .

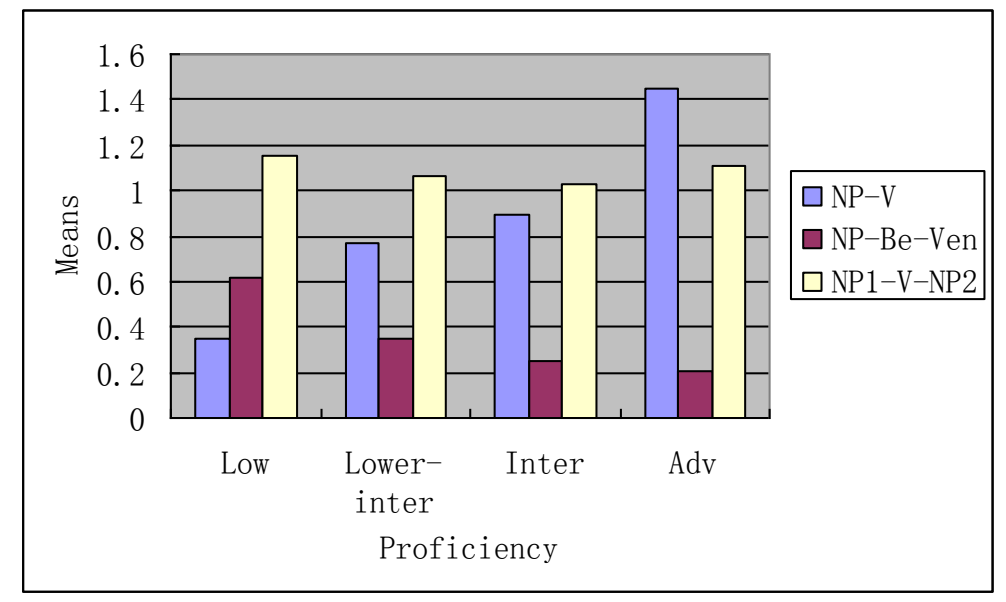

Figure 2: Means of Alternating Unaccusative Verbs in Three Structures

Figure 2 shows that the low-level Chinese learners' means of the NP-V structure was below 0.5, while that for the NP1-V-NP2 structure was above the 1.0. Given the fact the maximum correct scores for both structures were +2 , it is evident that the low-level Chinese learners had not acquired the intransitive use of alternating unaccusative verbs, but had basically acquired their transitive use. In contrast, the advanced learners' means of the NP-V structure was above 1.5, while that for the NP1-V-NP2 structure was also above the 1.0. This suggests that the advanced learners had acquired both the intransitive and transitive uses of alternating unaccusative verbs. In this sense, the acquisition of alternating unaccusative verbs was for Chinese learners to acquire the intransitive use of alternating unaccusative verbs on the basis of their transitive use. This finding is consistent with what Cai (2000) suggests.

\section{Contrast between Non-alternating and Alternating Unaccusative Verbs}

The acquisition problem of non-alternating unaccusative verbs is for Chinese learners to establish and reinforce the grammatical intransitive use of these verbs on the one hand and relinquish their ungrammatical passive and transitive uses on the other. The acquisition problem of alternating unaccusative verbs is for Chinese learners to incorporate the intransitive use of these verbs into their interlanguage grammar, which first develops the transitive use of these verbs. It is therefore evident that these two types of unaccusative verbs pose different acquisition problems to Chinese learners.

\section{Developmental Patterns}

\section{Non-alternating Unaccusative Verbs}

First, as far as the NP-V structure was concerned, the results of a one-way ANOVA showed that the differences between the four proficiency groups were highly significant, $F(3,150)=12.692, p=.000$. The results of a post hoc multiple comparisons test (Tamhane) revealed that the means of the low-level learners was not significantly lower than that of the lower-intermediate learners, but was significantly lower than those of the intermediate and advanced learners. The means of the lower-intermediate learners was not significantly lower than that of the intermediate learners, but was significantly lower than that of the advanced learners. The means of the intermediate learners was not significantly lower than that of the advanced learners. Therefore, a slow, non-continuous developmental pattern with a rising trend emerged in Chinese learners' acceptance of non-alternating unaccusative verbs in the NP-V structure.

Second, with respect to the NP-Be-Ven structure, the results of a one-way ANOVA showed that the differences between the four proficiency learnerss were highly significant, $F(3,150)=22.251, p=.000$. The results of a post hoc multiple comparisons test (Tamhane) revealed that the means of the low-level learners was not significantly higher than that of the lower-intermediate learners, but was significantly higher than those of the intermediate and advanced learnerss. The means of the lower-intermediate learners was significantly higher than those of the intermediate and advanced learners. And the means of the intermediate learners was significantly higher than that of the advanced learners. Therefore, a developmental pattern of initial stagnation and subsequent decrease emerged in Chinese learners' judgment of non-alternating unaccusative verbs in the NP-Be-Ven structure.

Third, as for the NP1-V-NP2 structure, the results of a one-way ANOVA showed that the differences between the four proficiency learners were highly significant, $F(3,150)=35.279, p=.000$. The results of a post hoc multiple 
comparisons test (LSD) revealed that the means of the low-level learners was not significantly higher than that of the lower-intermediate learners, but was significantly higher than those of the intermediate and advanced learners. The means of the lower-intermediate learners was significantly higher than those of the intermediate and advanced learners. And the means of the intermediate learners was significantly higher than that of the advanced learners. Therefore, a developmental pattern of initial stagnation and subsequent decrease emerged in Chinese learners' judgment of non-alternating unaccusative verbs in the NP1-V-NP2 structure.

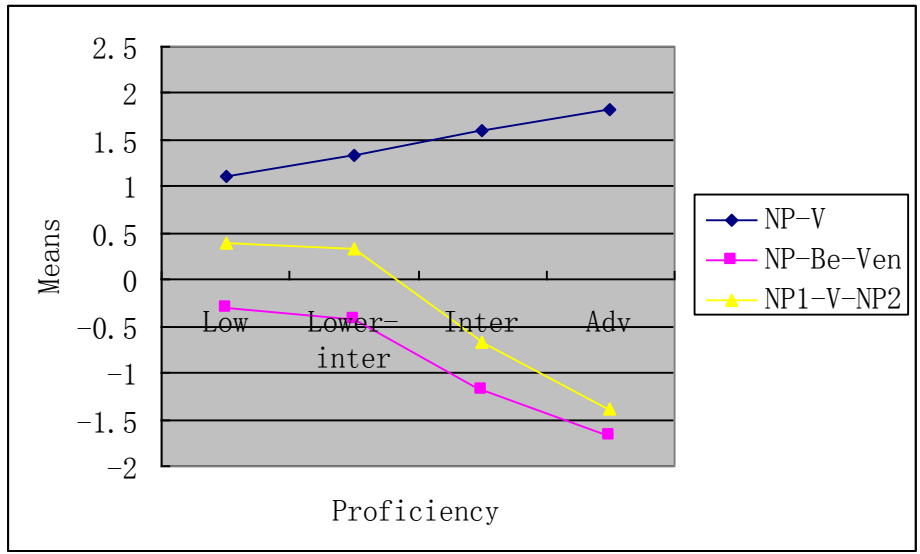

Figure 3: Developmental Patterns of Non-alternating Unanccusative Verbs in Three Structures

Summarizing the developmental patterns of these three structures, one can see that Chinese learners' judgments of non-alternating unaccusative verbs became more and more target-like with the improvement of their L2 proficiency. On the one hand, they became more and more acceptable of the grammatical intransitive use of these verbs in the NP-V structure, despite the fact that their change was slow and non-continuous. On the other hand, they became more and more unacceptable of the ungrammatical passive and transitive uses of these verbs in the NP-Be-Ven and NP1-V-NP2 structures, despite the fact that they were subject to an initial stagnation.

It is safe to say that Chinese learners achieved a better acquisition of non-alternating unaccusative verbs when their L2 proficiency improved. Their progress could be attributed to the facilitative function of positive evidence and the inhibitory function of indirect negative evidence. The positive evidence referred to the fact that the input always presents non-alternating unaccusative verbs in the NP-V structure. The availability of such positive evidence could help Chinese learners to establish such a syntactic representation in their minds. Since Chinese learners at upper levels normally received more positive evidence than their lower-level counterparts, it was natural that they were more acceptable of the intransitive use of non-alternating unaccusative verbs in the NP-V structure. The indirect negative evidence referred to the fact that the input never presents non-alternating unaccusative verbs in the NP-Be-Ven structure or the NP1-V-NP2 structure. When Chinese learners noticed the non-occurrence of these two structures, they were likely to refrain from accepting them. Eventually, they would reject them.

\section{Alternating Unaccusative Verbs}

First, as far as the NP-V structure was concerned, the results of a one-way ANOVA showed that the differences between the four proficiency groups were highly significant, $F(3,150)=14.879, p=.000$. The results of a post hoc multiple comparisons test (Tamhane) revealed that the means of the low-level learners was not significantly lower than that of the lower-intermediate learners, but was significantly lower than those of the intermediate and advanced learners. The means of the lower-intermediate learners was not significantly lower than that of the intermediate learners, but was significantly lower than that of the advanced learners. The means of the intermediate learners was also significantly lower than that of the advanced learners. Therefore, a developmental pattern of initial stagnation and later increase emerged in Chinese learners' acceptance of alternating unaccusative verbs in the NP-V structure.

Second, with respect to the NP-Be-Ven structure, the results of a one-way ANOVA showed that the differences between the four proficiency groups were not statistically significant, $F(3,150)=1.683, p=.173$. Therefore, a horizontal developmental pattern of no changes emerged in Chinese learners' judgments of alternating unaccusative verbs in the NP-Be-Ven structure.

Third, as for the NP1-V-NP2 structure, the results of a one-way ANOVA showed that the differences between the four proficiency groups were not statistically significant, $F(3,150)=.344, p=.793$. Therefore, a horizontal developmental pattern of no changes emerged in Chinese learners' judgments of alternating unaccusative verbs in the NP1-V-NP2 structure. 


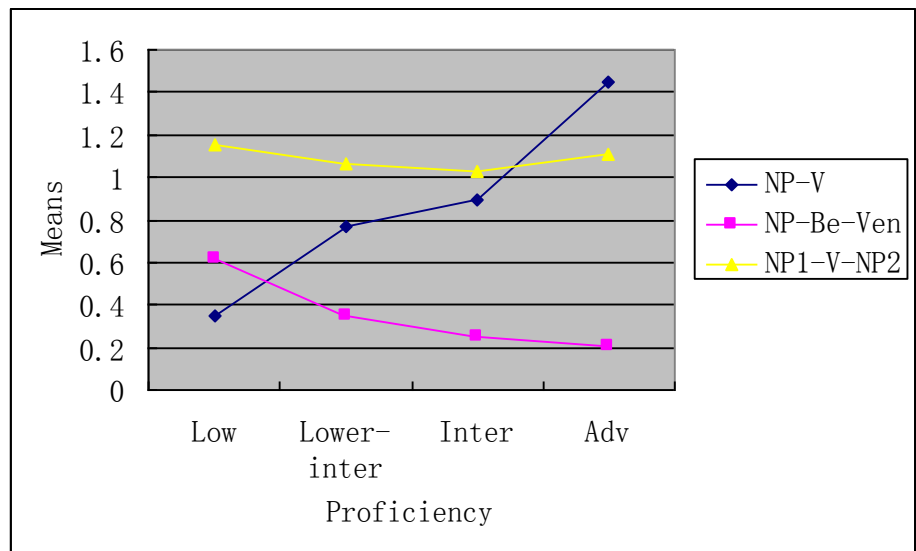

Figure 4: Developmental Patterns of Alternating Unaccusative Verbs in Three Structures

Summarizing the developmental patterns of these three structures, one can see that when Chinese learners' L2 proficiency improved, their judgments of alternating unaccusative verbs became more target-like only in the NP-V structure, but were subject to stabilization in the NP-Be-Ven and NP1-V-NP2 structures. There were different reasons for the developmental changes that happened to these structures.

Chinese learners' growing tendency to accept the intransitive use of alternating unaccusative verbs in the NP-V structure could be attributed to the facilitative function of positive evidence. That is, Chinese learners at upper levels normally received more L2 input that presents alternating unaccusative verbs in the NP-V structure. As a result, they gradually recognized that it is allowed to use alternating unaccusative verbs in this intransitive way and thus became more and more acceptable of such a usage.

Chinese learners' unchanged tendency to accept the passive use of alternating unaccusative verbs in the NP-Be-Ven structure could be explained by their insensitivity to contextual appropriateness. Given the fact that the passive use of alternating unaccusative verbs was designed to be contextually inappropriate as in His lifestyle was completely changed after he got married, Chinese learners were expected to become more and more unacceptable of such a usage when their L2 proficiency improved. But they did not show any signs of change. That is to say, Chinese learners at upper levels were no better than their lower-level counterparts in recognizing this error of contextual inappropriateness. Therefore, it is possible to say that Chinese learners' sense of contextual appropriateness did not improve with the improvement of their L2 proficiency.

As for the lack of changes in Chinese learners' acceptance of the transitive use of alternating unaccusative verbs in the NP1-V-NP2 structure, it was hard to explain. On the one hand, all the proficiency groups' means, as can be seen from Figure 4.6, were above 1.0, indicating that all of them had basically acquired the transitive use of alternating unaccusative verbs. On the other hand, their means, which were only slightly above 1.0, were somewhat distant from the maximum correct score of 2.0, suggesting that their acquisition was not completely successful.

\section{Contrast between Non-alternating and Alternating Unaccusative Verbs}

Summarizing the developmental patterns of non-alternating and alternating unaccusative verbs, one can see that that there were both similarities and differences between them. The similarities were found in the NP-V structure. That is, a developmental pattern with a general rising trend emerged in Chinese learners' acceptance of both non-alternating and alternating unaccusative verbs. The differences were found in the NP-Be-Ven and NP1-V-NP2 structures. That is, a developmental pattern with a falling trend emerged for non-alternating unaccusative verbs, while a developmental pattern of no changes emerged for alternating ones.

\section{Discussion}

This study finds that non-alternating unaccusative verbs are acquired earlier than alternating ones. This finding supports the Unaccusative Hierarchy Hypothesis (Sorace, 1995), which posits that non-alternating unaccusative verbs are core while alternating ones are peripheral and predicts that the former are acquired before the latter.

This study finds that non-alternating and alternating unaccusative verbs pose different acquisition problems. The former is for L2 learners to strengthen the grammatical intransitive use of non-alternating unaccusative verbs on the one hand and abandon their ungrammatical passive and transitive uses on the other. The latter is for L2 learners to integrate the intransitive use of alternating unaccusative verbs on the basis of the transitive use of these verbs. This finding is more complicated than Yip (1995).

This study finds that non-alternating and alternating unaccusative verbs undergo partially different and partially similar developmental patterns in three structural variations. However, none of the patterns are U-shaped. The lack of a U-shape casts doubts on the Unaccusative Trap Hypothesis (Oshita, 2001), which predicts such a developmental pattern for L2 acquisition of English unaccusative verbs. The rising trend of the grammatical NP-V structure for both non-alternating and alternating unaccusative verbs is suggested as a result of the facilitative function of positive evidence. The falling trend of the ungrammatical NP-Be-Ven and NP1-V-NP2 structures for non-alternating 
unaccusative verbs is suggested as a result of the inhibitory function of indirect negative evidence. It is evident that positive and negative evidence are conducive to the development of L2 acquisition of English unaccusative verbs in different aspects. Since both positive and negative evidence can be considered as L2 input, it is possible to say that L2 input plays an important role in L2 acquisition of English unaccusative verbs.

\section{CONCLUSion}

This study conducted a contrastive study of Chinese learners'acquisition of English non-alternating and alternating unaccusative verbs in terms of acquisition sequence, acquisition problem and developmental patterns. It found Chinese learners acquired the former earlier than the latter. And they were faced with different acquisition problems and underwent partially similar and partially different developmental patterns. This study focused on the between-group variations in L2 acquisiton of English non-alternating and alternating unaccusative verbs. Future studies are suggested to investigate this issue in greater details by examining the between-verb variations in L2 acquisiton of English unaccusative verbs, non-alternating and alternating alike.

\section{ACKNOWLEDGEMENT}

This paper is a result of two research projects. One is Variations in EFL learners' acquisition of English unaccusative verbs: Implications for computer-aided language teaching practices (14YJC740068) funded by the Ministry of Education, China. The other is Variations in Chinese learners' acquisition of English unaccusative verbs: Implications for computer-aided language teaching practices (2013SJB740030) funded by the Department of Education, Jiangsu Province.

\section{REFERENCES}

[1] Burzio, L. (1986). Italian syntax: A government-binding approach. Dordrecht: Reidel.

[2] Cai, Y. (2000). Prominence of causativization and its influence on L2 acquisition. Modern Foreign Languages 23, $174-182$.

[3] Deguchi, A. \& H. Oshita. (2004). Meaning, proficiency and error types: Variations in nonnative acquisition of unaccusative verbs. In Foster-Cohen. S. H., M. S. Smith, A. Sorace \& M. Ota (eds.), EuroSLA yearbook. Amsterdam: John Benjamins, 41-65.

[4] Hwang, J. B. (1999). Learnablity and the L2 development of English unaccusative verbs. Journal of the Applied Linguistic Association of Korea 15, 65-87.

[5] Ju, M. K. (2000). Overpassivization errors by second language learners: The effect of conceptualizable agents in discourse. Studies in Second Language Acquisition 22, 85-111.

[6] Oshita, H. (2001). The unaccusative trap in second language acquisition. Studies in Second Language Acquisition 23, $279-304$.

[7] Perlmutter, D. (1978). Impersonal passives and the unaccusative hypothesis. In Proceedings of the 4th Berkeley Linguistics Society. Berkeley: University of California, 157-189.

[8] Sorace, A. (1995). Acquiring linking rules and argument structure in a second language. In Eubank. L., L. Selinker \& M. S. Smith (Eds.), The current state of interlanguage: Studies in honor of William E. Rutherford. Amsterdam: John Benjamins, 153-175.

[9] Yip, V. (1995). Interlanguage and learnability: From Chinese to English. Amsterdam: John Benjamins.

[10] Zobl, H. (1989). Canonical typological structure and ergativity in English L2 acquisition. In Gass, S. \& J. Schachter (eds.), Linguistic perspectives on second language acquisition. Cambridge, UK: Cambridge University Press, 203-221.

Junhua Mo was born in Changzhou, China, in 1977. He received his PhD in applied linguistics from Nanjing University in 2008. Since then, he has been teaching English in School of Foreign Languages, Suzhou University. His major interests include second language acquisition, syntax and corpus linguistics. 